\title{
Microgrids Literature Review through a Layers Structure
}

\author{
Miguel Carpintero-Rentería ${ }^{1, *(\mathbb{D})}$, David Santos-Martín ${ }^{1}\left(\mathbb{C}\right.$ and Josep M. Guerrero ${ }^{2}(\mathbb{C})$ \\ 1 Department of Electrical Engineering, University Carlos III of Madrid (UC3M), Avda. De la Universidad 30, \\ Leganés, 28911 Madrid, Spain; dsmartin@ing.uc3m.es \\ 2 Department Energy Technology, Aalborg University, 9220 Aalborg, Denmark; joz@et.aau.dk \\ * Correspondence: micarpin@ing.uc3m.es; Tel.: +34-9162-488-53
}

Received: 25 October 2019; Accepted: 11 November 2019; Published: 18 November 2019

\begin{abstract}
Within a distributed generation (DG) system, microgrids (MGs) are an alternative approach that may provide both resiliency and efficiency benefits. In this review, an analysis of both research and industrial documents was done. In order to establish a solid foundation of the MGs concept, a comparison of various definitions written by distinguished authors has been made. Segmenting the information of MGs into layers facilitates its analysis, search, and comparison. Therefore, this paper continuous with a layer approach from other studies and incorporates the concept of the environment as a key element that has a high impact on the microgrid functional structure. With the foundation of the MG concept, an exhaustive literature review has been developed about the main microgrid layers, such as business, standard, climate, infrastructure or control, and operation.
\end{abstract}

Keywords: microgrids; distributed generation; smart grids

\section{Introduction}

Electrical energy demand is expected to increase by $30 \%$ in 2030 compared with the consumption levels of 2012, due mainly to population and economic growth [1]. In addition, according to the International Energy Agency, the incremental global investments in the energy sector through 2035 are estimated at $\$ 40$ trillion [2]. However, the energy is not produced only in large generation plants any more as it was many years ago [3]. Owing to new standards and global arrangements, the energy generation model is changing, and from those changes originate new opportunities. One opportunity is for distributed generation (DG) technologies to be the way for renewable energies to become a relevant segment of the electricity market. This decentralization could help tackle challenges like reliability, resiliency, or reducing greenhouse emissions, as well as producing benefits for consumers and producers $[4,5]$. Microgrids (MGs) are the ecosystem that may provide that decentralization of the generation resources.

There are many definitions about what a microgrid is; however, many authors agree on three key components that microgrids may share: Generation and demand control systems, clearly defined boundaries, and island capabilities [6-8]. Distributed electric generation can be from both renewable and traditional energy resources. Storage capabilities may be included as well. Microgrids are predominantly electrically based, operating in AC or DC, but they can incorporate thermal components for a heating purpose. Since the demand is close to those generation points, the boundaries of the system have a smaller scale than the main grid. A microgrid can operate independently from the grid in "island" mode or connected to it [9-12].

The uncertainty and intermittence of the renewable generation resources create a challenge in the administration of energy for any kind of system [13]. In microgrids, the control system, which includes the energy management system (EMS), must be used to govern the flow of energy and to decide 
between being connected or disconnected from the main grid. It also has a key role for optimizing the costs and the reliability of the power supply. At the same time, the control system oversees the primary, secondary, and tertiary controls, providing stability in the electrical system [14].

A systematic review guideline from the software engineering research field has been followed and adapted to identify the most relevant research and industrial documents about MGs [15]. This methodology along the layer structure allowed the authors to analyse a vast amount of information in a more rigorous and consistent way. The layers structure served as a template to classify the different research questions and organise and evaluate the information.

The following article will be focused on what microgrids are and how they can be structured. Initially, in the microgrid concept section, various definitions are discussed. Some basic knowledge is also presented, such as advantages and drawbacks. Section 3 analyses different layers of the MGs. A layer corresponds with a topic from which a MG can be studied, such as the business perspective among some others. In addition, some conclusions to future trend studies comprise the closure of the document.

\section{The Microgrid Concept}

During this section, a broad perspective of what a microgrid is will be presented. Starting with the definitions established by different organizations and researchers, a common understanding will be settled. From that point, the types of microgrids along their benefits will be covered. Also, the structure of a microgrid is discussed.

\subsection{Definitions}

There are many definitions about what a microgrid is [6-8,16-23]. All of them are extremely similar with little variance. There are three common factors which they all share: (a) islanded and grid connected functionalities; (b) clearly defined electrical boundaries; and (c) a control entity able to manage the energy resources along the loads. A microgrid structure concept similar to the one proposed in [7] and can be seen in Figure 1.

The concept of a microgrid was not the same from the beginning and, according to [9], a microgrid was seen from a very broad perspective in the very beginning as a power subsystem gathering generation and loads. After a time, it was established that microgrids worked on a distribution level, and later on, their islanding capability was finally presented. Even though nowadays the concept of a microgrid is not universally accepted as we have seen, in [24] the authors go even further and imply that there are also differences depending on the region of the world. According to them, the US perspective is that a microgrid can supply both heat and power, whereas in the EU approach, the heat supply is not usually considered.

Apart from microgrids built on islands or remote areas, the concept of a microgrid implies being connected to a stronger grid. Actually, many of its benefits come along with this capacity of connection and disconnection. For the purpose of islanded functionality, it is adequate for the microgrid to have an installed generation capacity exceeding the maximum load. In any other case, some loads may be sacrificed when the microgrid operates disconnected from the main grid.

Within its boundaries, the microgrid may integrate generation and responsive loads as well as storage systems. It should be seen as a single controllable entity by the main grid, which is a similar perspective that virtual power plants have $[25,26]$. The main difference between them is the islanded capability. In many cases, the microgrid is located at a LV level with some exceptions where it can have a medium voltage (MV). Some authors also make distinctions considering the power supplied to the microgrid, clustering them as picogrids or nanogrids [24]. 


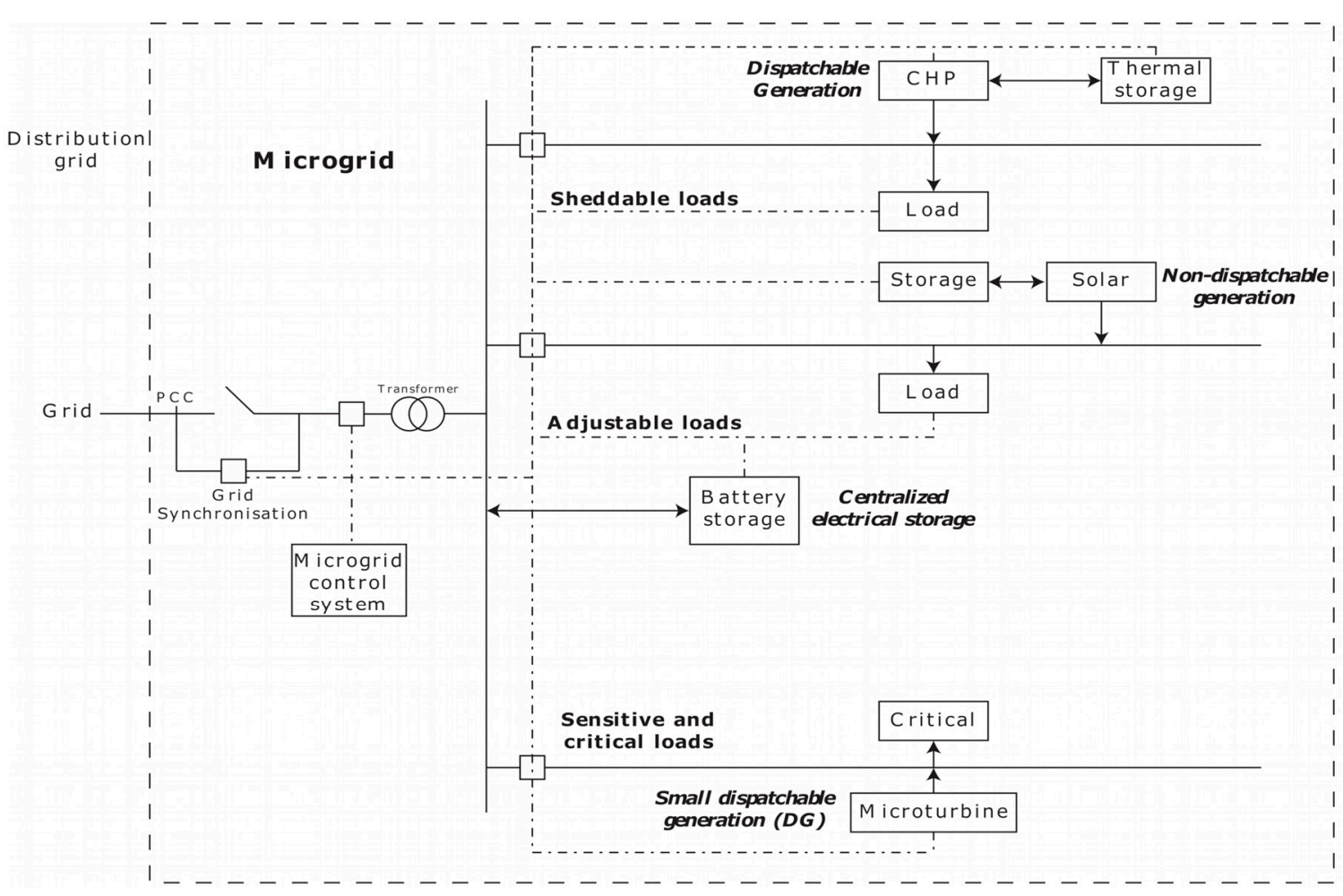

Figure 1. AC microgrid structure and components example.

The benefits of microgrids are very similar in both industrial documents and scientific research. All of them imply that MGs are reliable and efficient [8,16,27-32]. In almost all analysed publications, reliability and efficiency are described from different perspectives. The essence of energy reliability is related with one of the main characteristics of microgrids: its islanded functionality. The efficiency, in contrast, is the result of many factors, but the most repeated one is the characteristic of having the generation close to the demand. However, microgrids have many more benefits. For instance, [16,27] conclude that a microgrid is also a system independent from fuel variable prices since it is an adequate environment to implement renewable generation sources. The ability of microgrids to give access to remote areas where the main grid cannot reach, mainly due to excessive costs, is also pointed out. More renewable sources have the benefit of reducing harmful emissions as a consequence as it is denoted by [8]. In that same document, the most extensive study about the benefits of microgrids is developed. It is not only divided into direct or indirect benefits, but also relates them to the microgrid stakeholders. The security benefit is outlined in [28,29]. It is related with resiliency, but it is more focused on the detection and prevention of external disruptions, which is a subject of study in smart grids. The job creation benefit is explained by [16] and is related with local jobs, not only in maintenance. Benefits usually imply economic advantages, and some of them are studied in $[8,33,34]$.

Despite MGs having many benefits, some of their main characteristics need to be further analysed. In [31], the main barriers for a wider adoption of MGs are shown. The main enablers to avoid the proposed barriers are also discussed. Both topics are evaluated with different utility acceptance levels. For instance, when changing from grid connected to islanded, many security and economic issues may come to mind. The concern of utility regarding connection tariffs, among some others, are shown in [28]. In this manuscript, the relationship among the different stakeholders and their main goals are discussed. According to them, regulatory entities have a key role in the relationship among MG agents. Regarding technical and security features, general interconnection requirements are established in [35]. Technical issues related with intentional and unintentional islanding are also treated. Other manuscripts like [36] also analyse the interconnection requirements from the technical control perspective. 


\subsection{Microgrid Functional Structures}

There are different perspectives on how to differentiate the microgrid functional structure. Most articles focus on just one of the structures, but sometimes more are handled [9,17,37-39]. To clearly classify and asses the information of these structures, a layer-based approach can be followed.

Some authors already used a layer-based microgrid model to present a clear division of what functions this power system has. Martin-Martínez adapted in [24] the layer-based concept of CEN-CENELEC-ETSI into a microgrid perspective [40]. Maitra in [41] also chose a similar visualization of the microgrid and used it from a controller point-of-view. Due to its simplicity and clarity, this paper brings back this concept and adds some different conditions to explain and develop this article.

Martin-Martínez et al. [24] differentiates a microgrid in five layers. Those layers are regulatory framework, business models, intelligence, communications, and infrastructure. A disaggregation is also made into various levels (MG, nanogrid, and picogrid) according to the size of the subset of the grid. In [32], the technology in a MG is also divided into five layers. From Layer 0 to Layer 3 as he proposes would differentiate the physical equipment, the system protection and control, the automation and control, the monitoring, and scheduling. Then, Layer 4, optimization and dispatch, with the energy market, grid, and transactive operations as the last layer.

In this manuscript six different layers have been differentiated. Three of them are considered to have interactions mainly with external conditions to the MG. These are called, external layers and can be differentiated into policies and standards, business, and climate conditions. Most of their features depend on the environment and the location where the MG has been built. In contrast, the other three are called internal layers and have mainly interactions between other layers. These are separated into infrastructure, communications, as well as operation and control. In Figure 2 the six layers are represented. The internal layers are the inner ones, while the external layers are the outer ones.

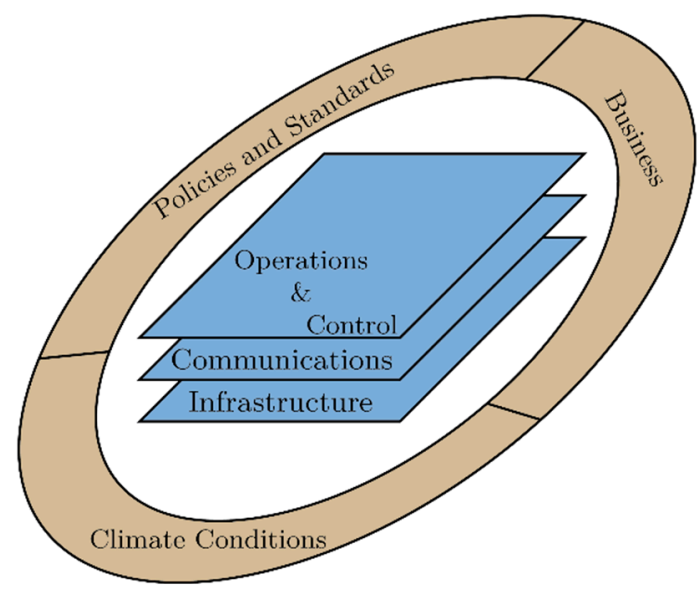

Figure 2. Microgrid layer structure.

Despite it mainly being used in companies from a project management perspective, conducting an analysis of the environment and identifying the relations and risks associated is a key factor of success in any kind of project [42-44]. A microgrid, as a project, should consider all of this, and thus a different approach is followed in the layer concept within this article, where the external conditions to the microgrid are analysed to see the interactions among all the layers. Within the following section, most of the layers will be reviewed.

\section{Microgrid Layers}

There are different perspectives from which to study a MG. For the sake of clarity, each of them was divided into six different layers. Despite there being many literature reviews encompassing a MG analysis, this paper aims to point out how the external conditions of a MG affects some layers while the 
others interact mainly between them. An exhaustive literature review has been developed to analyse the layers and study their interactions.

It is worth noting that some authors agree that microgrids have three main barriers for a wider implementation in the world. They refer to the business, policy, and technological barriers. However, they also conclude that most of the problems related to these barriers may eventually be solved, and the adoption of microgrids will be more extensive [12].

The barriers previously cited concur with three of the six layers presented here. Two of them within the external layers. To operate the microgrid, a close relationship must exist between all of the layers of the microgrid and the environment. So, there is a special emphasis on the approach of the control and optimization layer, considered a key function in a microgrid by [14] and the mechanism that holds all of the layers together in a microgrid.

\subsection{Policies and Standards Layer}

Regulatory barriers stand at the top of the three barriers mentioned above that prevent MGs from having a wider adoption in the world. According to [45], in the US, utility franchise rights, the threat of being subject to public utility regulation, and the lack of microgrid financing models and performance metrics are the main obstacles that microgrids are experiencing and therefore not achieving a wider deployment. Moreover, the impact in grid-connected microgrids is even higher.

All throughout this section, the Policies and Standards Layer (see Figure 2), two types of documents may be differentiated. First policies scenarios are shown, where principles adopted by an organization or a country in most of cases are analysed. Then standards, which do not provide mandatory technical specifications to be implemented but are highly suggested because they are considered to be minimum requirements in the system.

There are a multitude of policy scenarios widely adopted by many countries; emission taxation and supporting policies for renewable generation units are two examples. For instance, there have been many episodes in Spain, the UK, and Italy where a policy intervention had a significant impact, in this case to solar PV installation [46]. In the same article, it is also suggested that an over-regulatory and policy dependence may expose businesses to continuously deal with the regulatory framework and create risks for these companies in the sector where they operate. So, in conclusion, they suggest that policy makers must work along with businesses to increase long-term business models' sustainability, avoiding regulatory dependence. According to [47], in North American locations, emission taxation has little effect on the microgrid economics and operation whereas heavy incentives for renewable usage have a high impact on microgrid usage. Nevertheless, a readjustment on public policy to reduce emissions would change the future microgrids' designs to rely on microturbines. It also suggests that exporting power to the main grid is not rewarded due to issues with quality regulation and reverse flows. In [48], it is also pointed out that interconnection tariffs and carbon taxes are important parameters that policy makers have the power to deal with. A good management of policies performed by this collective may increase the deployment of microgrids all along the grid. They bring up the idea that policy makers, with the right policy framework, are focused on strategies to decentralize the main grid, which may lead to a decrease in customer energy costs. The impact on carbon taxes, economic incentives, mandatory emissions reduction, and mandatory minimum participation percentages of renewables are topics examined in [49]. Despite policy measures considering a broad spectrum of microgrid sizes, from a building to entire communities, they also suggest that the effects of microgrid size have not been examined in the literature yet.

According to [50] in the European Union (EU) there are not specific policies about MGs. Nevertheless, the manuscript gathers different regulations related to the main MG components, such as grid connection, renewable energies and self-consumption, as well as energy storage. Different incentives applied by EU countries are also discussed. The particular case of Spain in comparison with other EU members is presented. In [51], it is also stated that most of the countries have not developed a particular regulation for microgrid integration. Regarding the EU, it is said that advanced 
research has been made on the topic of MGs along energy policies to push a single energy market with large renewable penetration. The main topics that policies and standards should encompass are also summarized. In [52] a study of the power grid from a macro and micro level is developed. Regarding the MGs, it is said that within the EU, the MG policy paradigm should be stated at regional level. In contrast the manuscript states that in east Asia, with a partial liberalized market, MGs encompass some national specific goals. In Japan, islanding capability is necessary due to the high rate of earthquakes whereas Singapore is leading the rural electrification in the continent. With a deep look into the history and current status of the electricity market in China, Reference [53] identifies the smart grid technology as a way to address the commitments to global climate change, diverse economic requirements, or consumption in the country. Since the initiative to develop smart grids lies in the state, the authors encourage the institutions to integrate this technology, closely related with MGs. Regarding the USA, Reference [54] did a review of MG development with a special focus on policies. In the annexes of the manuscript, there is a table summarizing microgrid-related regulations at federal, state, and utility levels.

Regarding the technical standards and guidelines, the aim of these documents is to address the main functions that are common to all microgrids. Related to microgrids are six main documents. The IEEE 1547.4 is a guide for the design, operation, and integration of distributed resources' island systems with electrical power systems, focused on DER intentional islands that we may refer to as microgrids. The new IEEE 1547 revision [35] from 2018 also takes into account control capabilities, such as the voltage ride trough, the frequency ride trough, or the rate of change of frequency. The IEEE 2030.7 discusses the specifications of microgrid controllers to properly handle the operation and control layer, or how it is named in the standard, the microgrid EMS, common to all microgrids and analysed regardless of the architecture or jurisdiction. The IEEE 2030.8 is a new standard for the testing of functional and performance minimum requirements along their procedures to enable verification, quantification, and comparison performance of the MG controllers at the PCC. Two core functions are tested. The dispatch function of MG assets in both operating states, grid-connected and isolated. The transaction function where connecting to or disconnecting from the grid capabilities are also tested. This testing planning may facilitate a wider adoption of standard microgrid controllers [55]. The following two guidelines are referred to as the IEC 62898 series. In these two documents, MGs are considered as AC electrical systems at a low or medium voltage level. DC microgrids are not covered along the series. The IEC 62898-1 is named as a guideline for microgrid projects planning and specification [56]. In addition to planning, MG applications, generation, and load forecast, or technical requirements for microgrid connection, control protection, and communication are also covered in the document. The IEC 62898-2 named guidelines for operation and control [57]. Along this document, all issues are conceived under two different approaches. Grid-connected and islanded modes as they define it. Response characteristics, basic control strategies, protection, power quality and requirements for energy storage systems, communication, monitoring or synchronization, and reclosing are the main topics addressed in the guideline.

The IEEE 1547.4 is an overview of different microgrid configurations and determines how the system should be handled in various core situations, such as the transition to island mode, island mode operation, or the reconnection mode. According to other normative references such as IEEE 1547 or ANSI/NEMA C84.1-2006, what quality grid requirements should be considered in these three modes are detailed, for example, real and reactive power conditions, the magnitude of the load, the load shape, the load and generation balance, and so on. In another context, the requirements and considerations for the adequate planning of the microgrids are shown. The last section of the document discusses the different approaches and strategies to the operation of the microgrid, referencing adequate sources when concrete values should be taken into account [58].

The IEEE 2030.7, focused on the control layer, will be further discussed in the optimization and control section. Its aim is enabling the interoperability of different controllers and components needed in the microgrid EMS and setting up a standard microgrid control system. It focuses on AC 
systems and does not cover some topics such as planning and design of microgrids, power exchanges, communication systems, or connections between microgrids [7]. The IEEE 2030.8 is settled under the same context of MG controllers provided by the IEEE 2030.7.

\subsection{Business Layer}

The literature reviewed about the business layer (see Figure 2) has been divided into two parts, each of them corresponding with one paragraph. The first one will expose business cases closely related with policies whereas in the second and third paragraph the literature does not cover any type of regulation or standard.

Business cases expose legal, social, financial, and environmental approaches from a company perspective [40]. These external conditions to the project greatly influence how the microgrid works; so, the literature related to this theme embraces it from a perspective beyond the scope of the microgrids themselves. In fact, the business layer of a microgrid is strongly related to the policies and regulations of the region or country where it operates. They are so closely related that according to [46], the current DER business models, more settled than those used in microgrids projects, are more driven by regulatory and policy factors than by technological factors. With the same approach [59], it suggests that business and legal barriers are often more difficult than the physical ones and introduces some of those barriers. In [48], through analysing the business model of a microgrid, research concludes that policy makers have the power to guide the microgrid landscape by increasing its deployment as well as have the control over different key cost parameters. Following a literature review, questionnaires and interviews in [28] suggest that the lack of standardised regulation of microgrids, in this case referring to the US, and the disincentives for utilities to permit them collide with the main advantages that microgrids can offer for consumers. The aim of [60] was to inform policy makers and industry participants about new business models to evolve the traditional electric networks. Among different proposals, microgrids are shown as a relation between consumers and third parties. According to [61], change in MG business models with the support of regulators is needed to coexist with utilities. Taking into account the regulatory framework, in [62], Costa identifies and evaluates the prices and benefits when deploying a microgrid project and how these influence the relationships between the stakeholders within a microgrid. While certain countries experience a transition to a more liberalized energy market, reference [63] suggests that regulations in the energy sector are able to create or even tear apart new business models.

Stepping aside from the implications of regulations on the business layer, there have been other studies suggesting different business models for a microgrid project. For instance, reference [64] creates a systematic methodology to create a business case. According to them, the reliability of the microgrid and its justification are influenced by these business cases. In [12], due to the differences between some markets being very regularized and others being more liberalized, a general discussion of different business models is presented. They were done from two perspectives: One, the internal market of a microgrid with the relationships between owners and major stakeholders; and two, the external market, taking into account policies, energy markets, and ancillary services. In [65], by comparing two types of microgrids with one very close to a testbed and the other more close to the commercial segment, they identify the differences between them from technical and market perspectives-two out of the three microgrid barriers. The result of the analysis corresponds to the responsibilities and benefits for the stakeholders involved in the microgrid. For microgrids performing well during resiliency events, authors in [66] discusses the goals, operating constraints, and business models that these resilient microgrids have compared with the rest of the other kinds of microgrids. A financial and business model perspective has been taken into account in [67]. Proposing local management structures based on cooperatives or hybrid systems, different business models, and tariff alternatives depending on social cohesion are suggested in the article. Authors in the reference [68] establishes that a business case can be defined according to some benefits that microgrids have that the author establishes. In [63], the decentralization of energy data exchange platforms compared with 
the vertical integration of energy market operations is proposed as a way of greatly decreasing the infrastructure costs. This would allow the reduction of the entry barriers for microgrids to the energy sector. They have also identified a new category of microgrids, called dynamic microgrids, combining the elastic platform technologies and flexible business models of microgrids-as-a-service providers. Furthermore, they discuss the likelihood of implementing different business models by these new players. A higher implication of prosumers in a peer-to-peer market than consumers is suggested by [69] in order to face challenges such as the reliability of energy generation and consumption. The following literature review highlights the primary value streams offered by microgrids. Most of them are related to the economic feasibility of microgrids [34]. With some similarities, reference [70], show market drivers that may influence the development of microgrids from the business perspective of the Siemens company were discussed. Key factors are cybersecurity, growing demand, reliability for customers, and incentives by the government to propel microgrids along renewable electric generators. In addition to the market drivers, the benefits to the microgrid consumer are presented as well as the motivations to invest in microgrid projects as well as what the payback might be. The conclusions of [71] propose that each region or country, due to their particular government interests, regulations, or even the relative ease of doing business there, may reinforce certain business models of microgrid projects or prove to do just the opposite. Consequently, the business layer is highly susceptible not only to the regulatory framework but to the environment and must take into account all agents involved in order for the microgrid project to be economically successful.

Regarding the business and energy trading system, blockchain technology has implemented different transaction methodologies. Blockchain is a technology in which unaltered information is reliably transferred between agents. This concept is suitable for decentralised models like microgrids and hence different studies have been developed [69,72-78]. For instance, in [72] 14 different microgrid-use cases were studied. Most of them use blockchain technology as a peer-to-peer trading system and Ethereum as their platform. The author remarked that regulation and scalability are still issues to be solved. Another perspective of a business model is studied by [73], where blockchain technology is used to expire green certificates based on particular consumptions of the microgrid. In [74] some technical issues derived from the blockchain paradigm applied to microgrids are addressed. They propose a trading system in which power losses are considered. The effect of this changes the paradigm of the agents involved in the microgrid. A microgrid's economic efficiency regarding tariffs when interconnected or isolated is mainly solved by regulatory approaches, but blockchain technology can also be used. For example, Reference [69] designed a microgrid energy market based on blockchain technologies and developed seven requirements for an efficient market which then were evaluated in the Brooklyn MG project. In [75], a decentralised peer-to-peer energy market within a microgrid was developed. In this work payments were assigned without the influence of a microgrid or centralized operator. In [77], an electricity transaction methodology for microgrids based on blockchain technology and a continuous double action mechanism is also proposed. In this study, along the proposed model, a feasibility market study was conducted. The main outcomes of the model were the dynamic changes on the trading agents' information and a market strategy to optimize quotes and profits by enhancing the market efficiency. An electrical transaction model based on blockchain technology, with a special focus on security aspects was developed by [78]. A comparison between different analyses was conducted to prove the security and efficiency of the model proposed. Reference [76] proposes a peer-to-peer energy trading system within a weakly centralized operation of the microgrids in the power grid. Multidimensional behaviour is taken into account when developing the blockchain model. The referenced papers conclude that plenty of research is still needed to properly define and assess blockchain capabilities in the microgrid sector.

\subsection{Climate Conditions Layer}

Climate conditions are a consequence of the location and therefore are intrinsically related to it. Since there is a direct influence on the approach of other layers by the climate conditions, it is 
considered as an external layer (see Figure 2). The main influence the climate conditions have is with the internal layers; more concretely, with the infrastructure and the operation and control layers. The regulatory framework with its emissions taxes policies might also have a relationship, when geographical zones with low wind or sun have to rely on renewable generation technologies not as settled as wind turbines or PV.

It appears feasible that the weather and environment are key conditions when planning a microgrid. In reality, the infrastructure of the system and the generation technologies in particular are strongly related to this topic. It seems feasible to say that the location of the microgrid will determine the use of some technologies over others. For example, microgrids settled closer to the equator use much more PV than those settled at higher latitudes.

In the literature related to operation and optimization as well as control, it is said that the intermittence of the renewable generation technologies creates a challenge to be handled [79-86]. The forecasting of climate conditions is a widely used tool of not that long ago [80]. Forecasting methodologies are implemented on many kinds of microgrids. For example, [79] proposes an energy and operation management system with a probabilistic approach in order to face the uncertainties of the environment. In standalone microgrids, where it is critical to maintain a reliable and stable system, Reference [82] optimised the microgrid with a polished design of batteries in order to cope with the stochastic intermittence of the renewable sources. In [81], with a similar approach, the storage device as a necessary component to deal with the sun's intermittence was found. Due to the uncertainties in the operation of a microgrid derived from the unpredictability of renewables, Reference [83] developed a two-stage stochastic energy system model where the second stage's purpose is dealing with wind and solar power variability. By predicting one day ahead in the PV generation and one hour ahead in the wind power generation, Reference [84] sought to minimize the environmental impact on the microgrid. Through their machine learning methodology, they achieved a higher forecasting accuracy by reducing noise tolerance and improving generalisation. Reference [80] used a fuzzy ARTMAP neural network to forecast generation and created an efficient and accurate controller. Even some models with no information about the future climate conditions, hence the power output forecast, must consider those prediction errors as random values within certain distributions [85]. In order to properly handle the operation and control of the microgrid, climate data is needed, and models must take this into account. In [86], a deep analysis of the forecasting modules of the energy management system was done. According to them, the knowledge obtained by forecasting generation provides more flexibility to the system and gives the chance to take advantage of real-time grid pricing.

\subsection{Infrastructure Layer}

The infrastructure layer (see Figure 2) combines several types of components. By definition, it gathers DG with various energy sources, loads, control and operation resources, protection devices, communication systems, and cabling, as can be seen in Figure 1. It is not mandatory, but most microgrids also dispose of energy storage devices for power quality or energy management purposes. Two points of view are used in this layer. A discussion of AC, DC, and hybrid technologies starts this section. AC and hybrid MG examples can be seen in Figures 1 and 3, respectively. Besides, the second point-of-view is about the already mentioned electrical components, the architectures used to combine them, and the different microgrid classifications. In different studies, this layer has been denoted as a physical layer [24] or just treated as another piece in the microgrids' architecture. 


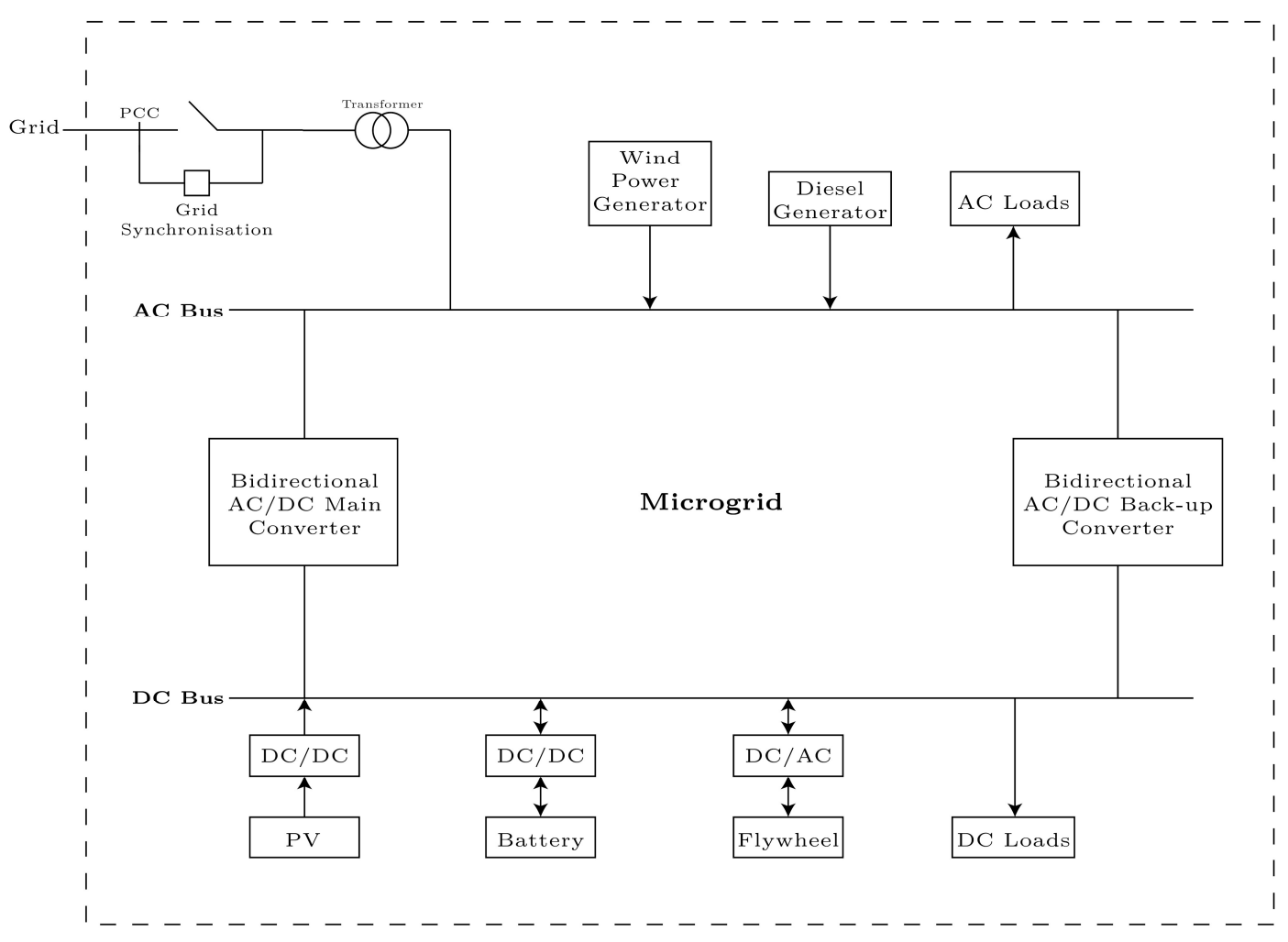

Figure 3. Hybrid microgrid structure and components example.

The advantages and disadvantages of both $\mathrm{AC}$ and $\mathrm{DC}$ microgrids are widely studied in literature. In [87], it is suggested that since the renewable sources such as PV generate in DC, these kinds of microgrids have the advantage of being easier to control mainly due to no need for DG synchronization, as well as the load fluctuations compensated for in the DC bus or easier coordination of the DGs. The main disadvantage of this kind of architecture is that inverters are required for the supply of AC loads. AC microgrids have a main disadvantage in that the control and operation are more difficult. Hybrid systems are supposed to have the main advantages and disadvantages of both worlds. A comparative study between AC and DC microgrids has been done in [88]. After describing the role of MGs in traditional grid systems, the study concludes that with more technology generating DC power, DC microgrid systems will soon have a bigger impact on the system. It summarizes that AC microgrid systems will have to address many challenges in comparison to DC systems. In [89], there are also proposed benefits of DC microgrids, in both energy efficiency and lower total cost of ownership over the lifetime project, compared to the current AC systems. In addition, the study establishes key components for a conversion system. In DC microgrids, contrasting with an AC schematic, an AC/DC gateway is proposed as a replacement for the traditional PV inverter and DC LED Driver instead of an AC-input LED driver, achieving 5\% more efficiency. In [90], an isolated DC microgrid is proposed for the power management of sustainable buildings. A key benefit is also denoted in the efficiency achieved in the overall production and consumption system, avoiding conversion losses and the control of reactive power. The schemes, technology, control, and operation of the system are also presented. With the premise of reducing AC-DC and DC-AC conversions, Reference [91] proposes a hybrid AC/DC microgrid. It shows a schematic of the technologies implied in the system along with the control schemes that are key to maintaining a stable operation on both of the AC and DC sides. In [92], there are established base requirements of what hybrid AC/DC microgrids should be. In [93], it is again indicated that there is a reduction of individual conversions between AC and DC with hybrid systems, and the complexities of the configuration, components, control, and operation of the microgrid are explained. 
As it has been pointed out in previous sections, the microgrid architecture and size can vary in many aspects. Reference [94] reviews existing microgrid architectures with actual real-world examples, analysing their basic components and classifications. In [9], the primary energy sources used in microgrids are cited. Along with the energy sources, there is a load classification and the wiring used to connect all of these technologies. The same article establishes a classification according to the network configuration in which the microgrids can be radial, rings, or a mesh. Additionally, microgrids are seen by the author as LV systems that, when grouped, create MV microgrids with greater generation technologies. Regarding the control architecture, Reference [95] proposes that MGs usually have local and master controllers, which means having control technology in not only each local source but also having controllers for high-level control objectives. This same hierarchical approach is done in Chapter 9 of Reference [92]. In [96], a methodology is formulated to plan the generation units, what renewable resources should be used, storage structures, and what types of energy conversion should be applied. The aim is to optimize the structure of multicarrier energy microgrids.

The infrastructure is usually used for classification purposes. For instance, Reference [87] shows different types of divisions, such as by loads/demand, capacity of the generators, or by AC/DC type. By demand, a microgrid is categorized as a simple microgrid, when it just contains one generator and has simple designs. Multi-DG microgrids have more complexity and utility MGs when the loads in a microgrid are prioritized based on user types. The division by capacity in the book is simple capacity (capacity below $2 \mathrm{MW}$ ), corporate microgrids (2-5 MW), feeder area microgrids (5-20 MW), substation area microgrids (capacity above $20 \mathrm{MW}$ ), and independent microgrids (off-grid areas). According to [87], no country has specified the voltage level connection of a generator within a MG. Nevertheless, in [9], MGs are differentiated into four categories depending on their voltage level. It is also stated that low voltage MG networks have a capacity constraint of several MW. Medium voltage networks conceive bigger MGs. Real world MG examples classified by voltage level are shown in [37].

Reference [37] also proposes the use of Multi-Microgrid (MMG) systems. It also concerns the classification of AC and DC microgrids in the MMG environment. Throughout the research there are some technical and constitutional limits that MMG systems should attend to. In addition, there are few application scenarios. It concludes that the architecture, components, and allocation are key challenges in the MMG performance, and their planning and design should not follow all the concepts and ideas of a single microgrid.

\subsection{Operation and Control Layer}

The control and operation in a microgrid are considered key factors in the success of the electrical systems due to many constraints, such as the control functionality in the islanded operation or the power exchange with the main grid. The scientific and industrial literature related to this topic is very large.

This layer (see Figure 2) has a singularity that is just software based or a combination of both software and hardware as we have seen in the infrastructure layer. According to the standard IEEE 2030.7 [7], the microgrid control system is within the boundaries of operation as it will be defined below. According to [14], both the operation and control are also done by the EMS, a term usually used for just operation purposes. In the following literature review, we will see how the boundaries between the control and operation are not that clear. For instance, according to the above-mentioned standard and [87], this section would take into account three hierarchical levels. The pure control in charge of local protection, such as the frequency, voltage, or $\mathrm{P} / \mathrm{Q}$ control, is established as a lower-level function. The core-level functions correspond with the dispatch functionalities and transition between grid connected and isolated modes. Higher-level functions are related with the operation along the main grid. Both the core and higher functions are related with the operation in MG systems, and each of them will be further developed below. Each of these levels is treated as a whole entity or by parts in the following two subsections. 
Centralized and decentralized control approaches are two opposite ways to control the MG architecture [10,97-99]. Different control approaches ranging from fully decentralized to fully centralized can be achieved by the classical control scheme with three levels: primary, secondary, and tertiary $[10,98,100-102]$.

\subsubsection{Control}

Several reviews about MGs' control are found in the literature [10,25,98-100,103,104]. An extensive review about the state-of-art control strategies and trends is done in [98]. A general overview of the challenges and desirable functions is also introduced. The operation of the microgrid works at the same level where the primary and secondary controls operate. The coordination between the MG and the main grid, where the economical optimization is done, works at the same level than the tertiary control. For each of these levels and hierarchies, a summary of the main approaches is also introduced.

The aim of the primary control is to accomplish a power balance in the microgrid. The most used technique in MGs is the droop control, which has a main drawback of frequency deviation. Reference [100] developed a review of hierarchical control strategies applied to microgrids and a deep analysis of primary, secondary, and tertiary levels along with the different techniques and methodologies involved. All management of the microgrid mentioned is treated from a stationary and dynamic perspective. Reference [99] reviewed the hierarchical control and energy management systems with their different strategies and generation technologies. Regarding the control, it follows the same classic structure of primary, secondary, and tertiary control. According to the authors, the secondary and tertiary controls should be implemented in the EMS. The centralized and decentralized functions are also discussed. From a multi-agent system (MAS) perspective, a three-level hierarchical strategy is also shown. A very extensive review of several issues related to microgrids is depicted in [10]. Regarding the operation and control, it explains and references the most common matters, such as hierarchical control structure (primary, secondary, and tertiary), control methods (master-slave or peer-to-peer), centralized or distributed control architectures, and different approaches like MAS, cooperative control, adaptive control, or tie-line power flow control inside these two sections. Through a constant comparison with the standard IEC/ISO 62264, Reference [25] reviewed the hierarchical control techniques, setting five classification levels for both energy management and control strategies. In accordance, Reference [36] proposes applying the same standard to MGs and ESSs with the increasing trend of researching control strategies. Throughout the article, it evaluates the idea and adapts the distributed control strategy to MGs.

There is a large difference between the control of islanded microgrids and grid-connected MGs [87,104-106]. When microgrids operate connected to the main grid, generators only need to maintain balance mainly because the frequency and voltage support come from the grid. Nevertheless, with islanded microgrids, DGs in the MG take the role of providing stability to both frequency and voltage, so they are usually under U/f and droop control. Microgrid control modes are also remarked upon, such as master-slave and peer-to-peer, where all DGs participate in the $\mathrm{P} / \mathrm{Q}$ regulation to maintain stability and the combined mode [97]. From the control perspective and also depending on whether the MG is connected to the main grid or isolated, the MG is supposed to extend its control functionalities. In the grid connected mode, the frequency and voltage are supported by the main grid, and the load supply is totally or partially done by the DG units. In contrast, while islanded, the frequency and voltage control must be done by the DGs as well as supplying both active and reactive power to the loads. Over the different control strategies analysed, the power flow control by current and voltage regulation should be highlighted. The main challenges when islanded are also pointed out throughout the article. Other analyses developed are that of the PQ and VSI control, autonomous control, and Q-V droop control among some others. The decentralized control strategy alongside a decentralized MG model is also presented. Decentralized secondary control system differences between grid-connected and islanded MGs are studied in [105]. The agents involved in this control system and the policies involved are also studied. To finish, a real test implementation is presented. Based on the stability and 
operation parameters, different microgrid classifications for MGs are proposed in [104]. Classifications from the operation of grid-connected or islanded modes are also shown where power voltage or frequency parameters are considered. In addition, a study of transient stability is done following the previous scheme classification.

With a hypothetical example of connecting two microgrids between them and with the grid, [101] explores some benefits along the operational and control challenges implied. A real power shortage, in which primary, secondary, and tertiary control strategies also need to be applied in order to re-establish first frequency stability and then optimal power output conditions, is explained. The constraints of a power exchange between two microgrids and the implications of implementing hierarchical control strategies are also explained step-by-step and with different figures. Reference [95] also considers the interconnection of multiple microgrids. In the implementation of MGs, this section discusses a four-stage implementation solution for any microgrid project. In contrast with other operation strategies, it establishes two levels of operation and control working tightly together: The local controller with its most common control methodology, droop control; and the master controller, which is also divided into two functional modes, the EMS and the protection coordination module. These two levels work together to optimize the operation of the MG and the interactions with the main grid.

\subsubsection{Operation}

Core level functions are more related to operation purposes. Scheduling, monitoring, and optimizing are the core functions of an EMS that manages the dispatch points of each distributed generator and storage system according to the demand and therefore constantly balances power in the grid. The energy management system must work between a connected and isolated state, including during the transition mode but also regulating the transition state. The standard IEEE 2030.7 is only focused on this layer, distinguishing the dispatch functionality and the transition function. According to the standard, core-level functions usually operate with a longer scale than lower-level ones. In this standard are noted the minimum functionalities of a microgrid as defined by them, which are very close to all definitions of Section 2. Both operating functions are explained along the standard with flow diagrams and a depth of explanation on each concept presented. Balancing generation and demand under normal conditions, re-dispatching resources are the core functionalities of the dispatch function in response to internal events and re-dispatching due to external orders or events. The transient function is not expected to cause any inconsistency with the interconnection requirements. Because of that, it must cope with four types of scenarios: unplanned islanding, planned islanding, reconnection, and black starts. In [107], including and beyond these two core functions is described a Cross-Layer Connectivity function between the different layers of the MG. The standard IEEE 2030.8 is also presented, the main goal of which is to evaluate the performance of a controller. In [35], the standard IEEE 1547, the exchange limits of active and reactive power under steady-state and transient conditions is defined. When disturbances occur, this standard also determines the prioritizing order of the DER to be selected or started to work. Despite technical requirements for DER in MGs may vary with the location, IEC 62898-1 outlines some planning techniques for the operation and control technical requirements [56]. The IEC 62898-2 is mostly focused in the operation and control of a MG. Although it also offers a glimpse about communication and monitoring, electrical energy storage systems, and protection, it is always shown from the operation and control layer perspective. In the IEC 62898-2 standard, and similarly to the IEEE 2030.7, the core functions of the MG control and operation are discussed, but also the dispatch and transient functions perspectives with the same four scenarios of the transient functionalities are analysed. Nevertheless, in this standard MGs are analysed from three perspectives. Non isolated grid connected MGs, non isolated islanded MGs, and isolated microgrids. According to this standard, non isolated islanded MGs are functioning in that condition for a limited time, so reconnecting back with the utility grid is needed sooner or later whereas isolated microgrids have no choice to be connected with a stronger grid [57]. Table 1 summarizes the different operation and control approaches from two of the standards analysed above. Despite the IEC 62898-2 
differentiating among three MG operation states, the IEEE 2030.7 just divide those states into two, when the grid is connected or islanded.

Table 1. Comparative operation and control strategies between IEC 62898-2 [57] and IEEE 2030.7 [7].

\begin{tabular}{|c|c|c|c|}
\hline & \multicolumn{2}{|c|}{ Non-Isolated MGs } & \multirow{2}{*}{ Isolated MGs } \\
\hline & Grid Connected & Islanded & \\
\hline 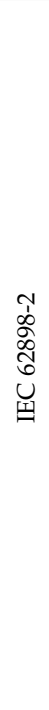 & $\begin{array}{l}\text { Monitoring, information exchange, and } \\
\text { control used to optimise loads and DER } \\
\text { operation between the MG and the } \\
\text { utility grid. } \\
\text { DER along other connected components } \\
\text { may comply the connection requirements } \\
\text { determined by the utility grid. } \\
\text { Regardless the topology, DER must comply } \\
\text { with the operating ranges specified in } \\
\text { IEC/TS } 62786 \text {. } \\
\text { Reactive power control schemes can be } \\
\text { applied to the MG to provide static } \\
\text { voltage support. }\end{array}$ & $\begin{array}{l}\text { Frequency and voltage among other } \\
\text { conditions should be monitored all } \\
\text { time for the reconnection back with } \\
\text { the utility grid. } \\
\text { EMS mayor function is to balance } \\
\text { the loads, generation and manage } \\
\text { storage capacity. } \\
\text { At least one DER shall operate U/f } \\
\text { mode to maintain voltage and } \\
\text { frequency and other DER shall } \\
\text { operate in PQ mode. } \\
\text { DER should be enough to maintain } \\
\text { voltage and frequency stability } \\
\text { along phase angle conditions } \\
\text { during isolation. } \\
\text { Voltage control using proper } \\
\text { auxiliary equipment. } \\
\text { Frequency regulation by DER active } \\
\text { power output adjustment through } \\
\text { frequency droop control, ESSs and } \\
\text { load shedding schemes. }\end{array}$ & $\begin{array}{l}\text { Ensure safe, secure and steady state } \\
\text { operation of the system. } \\
\text { EMS mayor function is to balance the } \\
\text { loads, generation and manage } \\
\text { storage capacity. } \\
\text { At least one DER shall operate U/f mode } \\
\text { to maintain voltage and frequency and } \\
\text { other DER shall operate in PQ mode. } \\
\text { Active and reactive power should } \\
\text { be balanced. } \\
\text { Voltage and frequency adjusted } \\
\text { between permitted ranges. } \\
\text { Load tracking, management } \\
\text { and shedding. } \\
\text { Dynamic response of DERs. } \\
\text { DER should have active and reactive } \\
\text { power generation capabilities to } \\
\text { maintain quality levels. } \\
\text { Black start capacity. } \\
\text { The ratio of electrical energy storage } \\
\text { capacity to the total of other DER shall } \\
\text { be much larger the non-isolated } \\
\text { islanded MGs }\end{array}$ \\
\hline 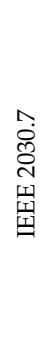 & $\begin{array}{l}\text { Control capacity of Individual or a group } \\
\text { of DERs. } \\
\text { Load management with curtailable loads. } \\
\text { Dispatch Control } \\
\text { Use of operation breaker, switches, and } \\
\text { other switching and control devices, } \\
\text { where needed } \\
\text { Voltage regulation using } \\
\text { adequate equipment } \\
\text { Implementation of power exchange levels } \\
\text { (P, Q) at the point of common coupling }\end{array}$ & $\begin{array}{l}\text { Control capacity of Individual or a gr } \\
\text { Load management with curtailable lo } \\
\text { Dispatch Control setting the net }(\mathrm{P}, \mathrm{Q}) \\
\text { Use of operation breaker, switches, an } \\
\text { where needed. } \\
\text { Voltage regulation using adequate eq } \\
\text { Frequency control using a reference } \mathrm{m} \\
\text { Maintaining and monitoring power } \mathrm{q} \\
\text { actions when needed }\end{array}$ & $\begin{array}{l}\text { up of DERs. } \\
\text { ads. } \\
\text { and the point of common coupling to zero. } \\
\text { d other switching and control devices, } \\
\text { ipment } \\
\text { icrogrid generator or storage resource } \\
\text { dality levels taking appropriate remedial }\end{array}$ \\
\hline
\end{tabular}

Several reviews about MGs' operation can be found in the literature [97,103,108-110]. Reference [108] is an extensive review deeply focused on optimization function objectives, including types of optimization typically used, constraints on the operation solution approaches, and tools used to solve energy management problems. It also gathers existing reviews related to the operation topic. The aim of the article is providing a solid foundation for more in-depth studies related to this topic. Alongside the control strategies discussed in the section below, Reference [103] provides a literature review regarding operation management or agent-based and multi-agent approaches. Through a literature review, Reference [109] presents an overview of different software tools and optimization algorithms to apply in the control and EMS techniques. The article is mainly focused on hybrid microgrids. Whereas the previous research was focused on hybrid systems, Reference [110] completes an extensive review on optimization techniques applied in all kind of MGs. Single and multi-objective, heuristic and metaheuristic optimization techniques along with optimization approaches to solve different planning problems are clustered into different tables with their own references. In [97], the bases of energy management and control systems are outlined. Moreover, the supervisory control or agents in a MG are explained in the article through the microgrid central controller, local controllers, or the interactions between them. The centralized and decentralized approaches are also discussed. Within the technological barriers, Reference [9] establishes some technical barriers related to the operation and control in a MG with real examples. Some examples discussed are dual-mode operation, regulatory power and frequency control, interconnection rules, and how to manage operation problems. 
There are different approaches in the operation of microgrids. A multi-agent system for EMSs is usually adopted. This system is adequate for plug-and-play capabilities, give robustness, heterogeneous device regulation, and high scalability and extensibility [105]. The main agents proposed are from the core-level like the data monitor or microgrid operator. From a high-level perspective, the DER operator is also referenced. Reference [18] presents the operation of a MAS applied in the operation in a microgrid. This approach is used to simplify the design of the algorithms. The main topics in the article are the operation of the MG and the interaction with the energy markets.

Much of the technical literature on microgrid operation focuses on system optimization [32,82, $83,92,95,102,104,106,109-115]$. A multi-objective methodology with a master-slave control strategy has been used to optimize the operations in the MGs with renewable sources, diesel generators, and battery storage, which is proposed in [82]. The main objectives presented are minimizing operation costs and battery life losses. Reference [83] proposes a two-stage stochastic EMS for grid connected MGs. The results prove the effectiveness in different conditions and real-world scenarios, minimizing the expected operational costs and power losses by accommodating the intermittency of renewable energy resources. A central controller with a hierarchical three-level topology is proposed in [111]. The main purpose is to provide an optimized dispatch and energy interchange with the main grid. The three layers proposed in the article coincide with the local, core, and high levels developed in this section. From bottom to high level, the layers detailed in the article are the micro source controller, the MG central controller (with the high functionality of minimizing operation costs of the microgrid), and the distribution management system, which refers to high-level microgrid operation but is beyond the scope of the research. As a lower-level function, reference [102] sets the primary control in a local environment. Regarding the control perspective in the core-level, the secondary control is established as the main system, the purpose of which is to return voltage and frequency levels to reference values in a higher-level hierarchical layer. This correction is the outcome of setting new dispatch points among the different DGs. In a core-level, Reference [116] develops a rule-based control method for a battery energy storage system to cope with the intermittency of renewable resources. This control method of batteries is easily applicable in other storage devices according to the article. In the higher level, Reference [102] establishes that the main goal is to set optimal economic dispatch, power management, and energy planning; then, once the optimization is performed, it relies on the secondary control to update the device statuses. Reference [112] proposes an EMS based on five major simulation models implemented on the MATLAB Simulink. The DC microgrid is controlled by fuzzy-logic strategy implemented in the EMS to achieve an optimization in the system. Two example features are selling additional electricity or the premise of increasing the Li-Ion battery life with dispatching strategies. A microgrid EMS is developed in [113], where the operation approach is divided into two strategies, so a coordinated actuation between the schedule and the dispatch layer must exist. The first one provides the economic operation in the MG based on forecasting data whereas the dispatch layer provides power setpoints based on real time data. The control in this EMS prioritizes power supply reliability over economic benefits. In [117], an EMS is developed based on rolling-horizon strategies using mixed integer optimization. Also, a neural network for two-day ahead consumption forecasting is developed. The system is tested using real data from an existing microgrid. By using the rolling horizon, the effects derived from forecasting uncertainties are supposed to be reduced. [118] presents a centralized EMS for isolated microgrids. The energy management system is formulated in a multi-stage programming problem, and also decomposed UC and optimal power flow. Due to the isolation, according to them, the centralized approach is the most appropriate strategy to be followed in these systems. With a slightly different structure, Reference [95] address the operation and control strategies in microgrids. This analysis also considers the interconnection of multiple microgrids.

Reference [106] presents a hierarchical EMS for standalone microgrids. It is designed for a diesel-wind-biomass MG with an ESS. The main purpose of the system is to reduce operation costs and make sure an adequate management of the state of charge of the ESS is done. The behaviour of the EMS is tested in a real-time simulation platform with the results supporting the main goals of the 
proposed system. The operation in [87] is divided into two modes, grid-connected and islanded mode. For both operation modes, flowcharts for optimal dispatch can be found within Chapter 4. Regarding optimization techniques, Reference [92] establishes some models for MG components also in Chapter 4. After presenting different techniques, the goal is applying a scheduled optimization, surpassing challenges of the combined heat and power microgrid model.

In [114], a MG modelling and high-level optimization strategy is proposed using mixed integer linear programming along model predictive control strategies. To assess the system, a case study applied in an experimental microgrid is used. All operations consider predictions about system behaviour, power generation, and demand forecast. A decentralized EMS for the coordination of the distribution system and networked microgrids is proposed in [115]. The network operator and the MGs are considered to have their own objectives, hence minimizing their own costs and self-managing their entities. The optimization solution is based on a decentralized bi-level stochastic algorithm founded on two levels. The first level solves the problems for each entity and conducts negotiations based on current penalties. The second level updates those penalties with the impacts between MG entities, looking for the optimal operation point. According to [32], higher-level functionalities can be responsible for increasing economic benefits by optimizing generation and storage with the market opportunities.

An EMS consisting of a prediction module, optimization module, and the online control of a single-phase high-frequency AC microgrid has been presented in [104] to optimize the operation costs. The hierarchical levels of the control system interchange information in an iterative mode, and as levels increase in the hierarchy, the time horizons also increase.

There are also blockchain methodologies for the operation of MGs. For instance, Reference [74] do not only focuses on economic aspects, but also in the energy dispatch, where a special focus on tracking energy losses is done. By including this information, the timing processing the information changes drastically. Other energy operation models are shown in Reference [72] where 14 different projects are analysed. For instance, one of the projects takes demand side response actions based on blockchain methods. Incentive methodologies to use renewable energy sources are also discussed in the manuscript.

\section{Conclusions}

The aim of this article is to bring together the MGs' layer concept, previously defined by various authors, with the external conditions of a MG. Segmenting the information into layers has proved to be a useful way to assess the information in a clearer way. This classification may also provide a solid foundation from which future studies may establish their MGs' models or projects.

Regarding the layer concept, within the external layers, the policies and standards layer interacts and affects not only the other layers but the deployment of MGs themselves. Despite that the use of DG standards has been adopted, new particular microgrid standards and policies are emerging. Regarding the business layer, it has been studied from two points of view, one related to different business models proposed by some authors and the other one showing how policies are very close related with this layer. The last external layer is how the environment and the climate differences have a key role into the selection of components and the approach followed in the other layers such as the operation and control strategies. Regarding the internal layers analysed, the infrastructure perspective is done again from two points of view, one regarding the electrical components involved and the other one regarding the architecture and strategy used to combine all of these different components. The last layer analysed is also considered as a distinctive and key factor by many authors. Widely studied, the operations and control layer is disaggregated into two-the strict control strategies analysed by the authors and the management and operation techniques used. All of them are proposed following the new schematic of the standard IEEE 2030.7, which differentiates between low, core, and high levels. Each one of the actions are implied in this layer. 
Throughout the analysed literature there are multiple definitions of a MG. Just two of those definitions are presented in a technical standard, but all of them share three common factors: (a) islanding capabilities, (b) clearly defined boundaries, and (c) control to operate both resources and loads.

Many of the articles reviewed in the literature were highly influenced by the environment, and hence a deeper analysis of the business, regulatory, and climate constraints is needed. Quite a repeated one is the relationship between the microgrid and the main grid market. Clear policies should establish rights and responsibilities in order to develop all technological advances proposed by MGs and the different control and operation solutions.

Author Contributions: M.C.-R., as first and correspondence author, coordinated the conception and writing of the manuscript. He also wrote and edited the manuscript before submitting it to the journal and participated in the review process. D.S.-M. contributed in the operation and control layer conception and writing process. Also, he has participated in the review process of the whole manuscript. J.M.G. provided his expertise regarding microgrids standards. His contribution is shown within the conception of the policies and standards layer as well as the standard comparison within the operation layer.

Funding: This research received no external funding.

Conflicts of Interest: The authors declare no conflict of interest.

\section{References}

1. U.S. Energy Information Administration. Energy Information Administration. International Energy Outlook 2016; U.S. Energy Information Administration: Washington, DC, USA, 2016; Volume 484, ISBN 2025866135.

2. International Energy Agency. World Energy Investment Outlook; International Energy Agency: Paris, France, 2014; Volume 23, p. 329.

3. REN21. Renewables 2018 Global Status Report; REN21 Publications: Paris, France, 2018; ISBN 9783981891133.

4. Pepermans, G.; Driesen, J.; Haeseldonckx, D.; Belmans, R.; D'haeseleer, W. Distributed generation: Definition, benefits and issues. Energy Policy 2005, 33, 787-798. [CrossRef]

5. Driesen, J.; Katiraei, F. Design for distributed energy resources. IEEE Power Energy Mag. 2008, 6, 30-40.

6. US Department of Energy. DOE Microgrid Workshop Report; Office of Electricity Delivery and Energy Reliability: California, CA, USA, 2011.

7. IEEE Power and Energy Society. IEEE Standard for the Specification of Microgrid Controllers in IEEE Std. 2030.7; The institute of Electrical and Electronics Engineers: Piscataway, NJ, USA, 2017; pp. 1-43.

8. CIGRÉ 635-Microgrids 1 Engineering, Economics, E Experience; WG C6.22; CIGRÉ: Paris, France, 2015; ISBN 9782858733385.

9. Soshinskaya, M.; Crijns-Graus, W.H.J.; Guerrero, J.M.; Vasquez, J.C. Microgrids: Experiences, barriers and success factors. Renew. Sustain. Energy Rev. 2014, 40, 659-672. [CrossRef]

10. Parhizi, S.; Lotfi, H.; Khodaei, A.; Bahramirad, S. State of the art in research on microgrids: A review. IEEE Access 2015, 3, 890-925. [CrossRef]

11. Comodi, G.; Giantomassi, A.; Severini, M.; Squartini, S.; Ferracuti, F.; Fonti, A.; Nardi Cesarini, D.; Morodo, M.; Polonara, F. Multi-apartment residential microgrid with electrical and thermal storage devices: Experimental analysis and simulation of energy management strategies. Appl. Energy 2015, 137, 854-866. [CrossRef]

12. Hatziargyriou, N. Microgrids: Architectures and Control; Wiley: Sussex, UK, 2013; ISBN 9781118720677.

13. Khodaei, A.; Bahramirad, S.; Shahidehpour, M. Microgrid Planning Under Uncertainty. IEEE Trans. Power Syst. 2014, 30, 2417-2425. [CrossRef]

14. Ton, D.; Reilly, J. Microgrid Controller Initiatives: An Overview of R D by the U.S. Department of Energy. IEEE Power Energy Mag. 2017, 15, 24-31. [CrossRef]

15. Kitchenham, B.; Charters, S. Guidelines for performing Systematic Literature reviews in Software Engineering Version 2.3. Engineering 2007, 45, 1051.

16. Siemens. Microgrids White Paper; Siemens AG: Erlangen, Germany, 2011.

17. Kondoleon, D.; Ten-Hope, L.; Surles, T.; Therkelsen, R.L. The CERTS MicroGrid Concept. In Integration of Distributed Energy Resources; CERTS Program Office: Berkeley, CA, USA, 2003; p. 32.

18. Dimeas, A.L.; Hatziargyriou, N.D. Operation of a multiagent system for microgrid control. IEEE Trans. Power Syst. 2005, 20, 1447-1455. [CrossRef]

19. Hayden, E. Introduction To Microgrids; Securicon: Alexandria, VA, USA, 2013. 
20. IEEE Smartgrid. Utility and Other Energy Company Business Case Issues Related to Microgrids and Distributed Generation (DG), Especially Rooftop Photovoltaics. Presentation to the U.S. Department of Energy by the IEEE Joint Task Force on QER, PISCATAWAY, NJ, USA, 6 October 2014; IEEE Power \& Energy Society: Piscataway, NJ, USA, 2014.

21. Lidula, N.W.A.; Rajapakse, A.D. Microgrids research: A review of experimental microgrids and test systems. Renew. Sustain. Energy Rev. 2011, 15, 186-202. [CrossRef]

22. Lopes, J.A.P.; Moreira, C.L.; Madureira, A.G. Defining control strategies for microgrids islanded operation. IEEE Trans. Power Syst. 2006, 21, 916-924. [CrossRef]

23. Lo Prete, C.; Hobbs, B.F.; Norman, C.S.; Cano-Andrade, S.; Fuentes, A.; von Spakovsky, M.R.; Mili, L. Sustainability and reliability assessment of microgrids in a regional electricity market. Energy 2012, 41, 192-202. [CrossRef]

24. Martin-Martínez, F.; Sánchez-Miralles, A.; Rivier, M. A literature review of Microgrids: A functional layer based classification. Renew. Sustain. Energy Rev. 2016, 62, 1133-1153. [CrossRef]

25. Palizban, O.; Kauhaniemi, K.; Guerrero, J.M. Microgrids in active network management-Part I: Hierarchical control, energy storage, virtual power plants, and market participation. Renew. Sustain. Energy Rev. 2014, 36, 428-439. [CrossRef]

26. Pudjianto, D.; Pudjianto, D.; Ramsay, C.; Ramsay, C.; Strbac, G.; Strbac, G. Virtual power plant and system integration of distributed energy resources. Renew. Power Gener. IET 2007, 1, 10-16. [CrossRef]

27. Wild, J.; Boutin, V.; Barton, P.; Haines, L. Microgrid Benefits and Example Projects; Schneider Electric: Paris, France, 2016.

28. Pacheco, F.E.; Foreman, J.C. Microgrid Reference Methodology for Understanding Utility and Customer Interactions in Microgrid Projects. Electr. J. 2017, 30, 44-50. [CrossRef]

29. Navigant Consulting. Microgrids Research Assessment_Phase 2; Navigant Consulting: Chicago, IL, USA, 2009.

30. Agrawal, P. Overview of DOE Microgrid Activities. In Proceedings of the Montréal 2006 Symposium on Microgrids, Québec, QC, Canada, 23 June 2006.

31. Schwaegerl, C.; Tao, L.; PeÇas Lopes, J.; Madureira, A.; Mancarella, P.; Anastasiadis, A.; Hatziargyriou, N.; Krkoleva, A. Report on the Technical, Social, Economic, and Environmental Benefits Provided by Microgrids on Power System Operation; Siemens AG: Erlangen, Germany, 2009.

32. Vaahedi, E.; Nodehi, K.; Heim, D.; Rahimi, F.; Ipakchi, A. The emerging transactive microgrid controller. IEEE Power Energy Mag. 2017, 15, 80-87. [CrossRef]

33. Basu, A.K.; Chowdhury, S.P.; Chowdhury, S.; Paul, S. Microgrids: Energy management by strategic deployment of DERs-A comprehensive survey. Renew. Sustain. Energy Rev. 2011, 15, 4348-4356. [CrossRef]

34. Stadler, M.; Cardoso, G.; Mashayekh, S.; Forget, T.; DeForest, N.; Agarwal, A.; Schönbein, A. Value streams in microgrids: A literature review. Appl. Energy 2016, 162, 980-989. [CrossRef]

35. Institute of Electrical and Electronics Engineers. IEEE Standard for Interconnection and Interoperability of Distributed Energy Resources with Associated Electric Power Systems Interfaces; IEEE Std 1547-2018 (Revision IEEE Std 1547-2003); The Institute of Electrical and Electronics Engineers: Piscataway, NJ, USA, 2018; pp. 1-138.

36. Palizban, O.; Kauhaniemi, K.; Guerrero, J.M. Microgrids in active network management—Part II: System operation, power quality and protection. Renew. Sustain. Energy Rev. 2014, 36, 440-451. [CrossRef]

37. Xu, Z.; Yang, P.; Zheng, C.; Zhang, Y.; Peng, J.; Zeng, Z. Analysis on the organization and Development of multi-microgrids. Renew. Sustain. Energy Rev. 2018, 81, 2204-2216. [CrossRef]

38. Li, Y.; He, B.L.; Yu, Q.Z.; Ji, Y.; Yu, H.; Wu, M.; Liu, H.T. Study and application of microgrid energy management system based on the four-dimensional energy management space. In Proceedings of the 2014 International Conference on Power System Technology, Chengdu, China, 20-22 October 2014; pp. 3084-3089.

39. Vaccaro, B.A.; Popov, M.; Villacci, D.; Terzija, V. An Integrated Framework for Smart Microgrids Modeling, Communication, and Verification. Proc. IEEE 2011, 99, 119-132. [CrossRef]

40. CEN-CENELEC-ETSI Smart Grid Coordination Group. Sustainable Processes; SG-CG/M490/E; European Commission: Brussels, Belgium, 2012; pp. 1-101.

41. Maitra, A.; Simmins, J. Grid Interactive Microgrid Controllers and the Management of Aggregated Distributed Energy Resources (DER); EPRI: Palo Alto, CA, USA, 2015.

42. Stakeholders, B. Project Management in a Dynamic Environment Balancing Stakeholders. In Proceedings of the 2017 IEEE European Technology and Engineering Management Summit (E-TEMS), Munich, Germany, 17-19 October 2017; pp. 1-6. 
43. Sauser, B.J.; Reilly, R.R.; Shenhar, A.J. Why projects fail? How contingency theory can provide new insights-A comparative analysis of NASA's Mars Climate Orbiter loss. Int. J. Project Manag. 2009, 27, 665-679. [CrossRef]

44. Aaltonen, K. Project stakeholder analysis as an environmental interpretation process. Int. J. Proj. Manag. 2011, 29, 165-183. [CrossRef]

45. Metelitsa, C.U.S. Microgrids 2017: Market Drivers, Analysis and Forecast Detailed Segmentation and Ownership Trends; GTM Research: Boston, MA, USA, 2017.

46. Burger, S.P.; Luke, M. Business models for distributed energy resources: A review and empirical analysis. Energy Policy 2017, 109, 230-248. [CrossRef]

47. Zachar, M.; Trifkovic, M.; Daoutidis, P. Policy effects on microgrid economics, technology selection, and environmental impact. Comput. Chem. Eng. 2014, 81, 364-375. [CrossRef]

48. Hanna, R.; Ghonima, M.; Kleissl, J.; Tynan, G.; Victor, D.G. Evaluating business models for microgrids: Interactions of technology and policy. Energy Policy 2017, 103, 47-61. [CrossRef]

49. Milis, K.; Peremans, H.; Van Passel, S. The impact of policy on microgrid economics: A review. Renew. Sustain. Energy Rev. 2018, 81, 3111-3119. [CrossRef]

50. Sanz, J.F.; Matute, G.; Fernández, G.; Alonso, M.A.; Sanz, M. Analysis of European policies and incentives for microgrids. Renew. Energy Power Qual. J. 2014, 8, 874-879. [CrossRef]

51. Mariam, L.; Basu, M.; Conlon, M.F. Microgrid: Architecture, policy and future trends. Renew. Sustain. Energy Rev. 2016, 64, 477-489. [CrossRef]

52. Van Hende, K.; Wouters, C. The regulation of microgrids in liberalized electricity markets in the EU and East Asia. Eur. Netw. Law Regul. 2014, 2014, 190-206.

53. Baležentis, T.; Štreimikiene, D. Sustainability in the electricity sector through advanced technologies: Energy mix transition and smart grid technology in China. Energies 2019, 12, 1142. [CrossRef]

54. Feng, W.; Jin, M.; Liu, X.; Bao, Y.; Marnay, C.; Yao, C.; Yu, J. A review of microgrid development in the United States-A decade of progress on policies, demonstrations, controls, and software tools. Appl. Energy 2018, 228, 1656-1668. [CrossRef]

55. IEEE Power and Energy Society. IEEE Standard for the Specification of Microgrid Controllers 2030.8; The Institute of Electrical and Electronics Engineers: New York, NY, USA, 2018; ISBN 9781504446082.

56. International Electrotechnical Commission. IEC TS 62898-1 Microgrids_Part1:Guidelines for Microgrid Projects Planning and Specification; IEC Publications: Geneva, Switzerland, 2017; ISBN 9782832243602.

57. International Electrotechnical Commission. IEC TS 62898-2 Microgrids_Part 2: Guidelines for Operation; IEC Publications: Geneva, Switzerland, 2018; ISBN 9782832260425.

58. IEEE STANDARDS Coordinating Committee. 21 IEEE Guide for Design, Operation, and Integration of Distributed Resource Island Systems_IEEE Std. 1547.4; The Institute of Electrical and Electronics Engineers: Piscataway, NJ, USA, 2011; ISBN 9780738166889.

59. Henderson, M. Microgrid Controllers. IEEE Power Energy. 2017, 15, 4-5.

60. Tayal, D.; Rauland, V. Future business models for Western Australian electricity utilities. Sustain. Energy Technol. Assess. 2017, 19, 59-69. [CrossRef]

61. Corum, L. The Future of Microgrid Markets. Bus. Energy 2015, 13, 36-41.

62. Costa, P.M.; Matos, M.A. Economic analysis of microgrids including reliability aspects. In Proceedings of the 2006 International Conference on Probabilistic Methods Applied to Power Systems, Stockholm, Sweden, 11-15 June 2006; pp. 1-8.

63. Rusitschka, S.; Sturm, M.; Lehofer, M. Disruptive potential and business model innovation through elastic microgrid-as-a-service (MAAS) platforms. In Proceedings of the CIRED Workshop 2016, Helsinki, Finland, 14-15 June 2016.

64. Quashie, M.; Bouffard, F.; Joós, G. Business cases for isolated and grid connected microgrids: Methodology and applications. Appl. Energy 2017, 205, 105-115. [CrossRef]

65. Tao, L.; Schwaegerl, C.; Narayanan, S.; Zhang, J.H. From Laboratory Microgrids to Real Markets-Challenges \& Opportunities. In Proceedings of the 8th International Conference on Power Electronics-ECCE Asia, Jeju, Korea, 30 May-3 June 2011.

66. Ortmeyer, T.; Wu, L.; Li, J. Planning and design goals for resilient microgrids. In Proceedings of the 2016 IEEE Power \& Energy Society Innovative Smart Grid Technologies Conference (ISGT), Minneapolis, MN, USA, 6-9 September 2016. 
67. Ubilla, K.; Jiménez-Estévez, G.A.; Hernádez, R.; Reyes-Chamorro, L.; Irigoyen, C.H.; Severino, B.; Palma-Behnke, R. Smart microgrids as a solution for rural electrification: Ensuring long-term sustainability through cadastre and business models. IEEE Trans. Sustain. Energy 2014, 5, 1310-1318. [CrossRef]

68. Joos, G.; Reilly, J.; Bower, W.; Neal, R. The Need for Standardization: The Benefits to the Core Functions of the Microgrid Control System. IEEE Power Energy Mag. 2017, 15, 32-40. [CrossRef]

69. Mengelkamp, E.; Gärttner, J.; Rock, K.; Kessler, S.; Orsini, L.; Weinhardt, C. Designing microgrid energy markets: A case study: The Brooklyn Microgrid. Appl. Energy 2018, 210, 870-880. [CrossRef]

70. Dohn, R.L. The Business Case for Microgrids; Siemens AG: Erlangen, Germany, 2011; pp. 1-9.

71. Gabriel, C.A.; Kirkwood, J. Business models for model businesses: Lessons from renewable energy entrepreneurs in developing countries. Energy Policy 2016, 95, 336-349. [CrossRef]

72. Meisel, M.; Fotiadis, L.; Wilker, S.; Treytl, A.; Sauter, T. Blockchain Applications In Microgrids. In Proceedings of the IECON 2017-43rd Annual Conference of the IEEE Industrial Electronics Society, Beijing, China, 29 October-1 November 2017; pp. 6153-6158.

73. Imbault, F.; Swiatek, M.; De Beaufort, R.; Plana, R. The green blockchain: Managing decentralized energy production and consumption. In Proceedings of the 2017 IEEE International Conference on Environment and Electrical Engineering and 2017 IEEE Industrial and Commercial Power Systems Europe (EEEIC/I\&CPS Europe), Milan, Italy, 6-9 June 2017; pp. 1-5.

74. Di Silvestre, M.L.; Gallo, P.; Ippolito, M.G.; Sanseverino, E.R.; Zizzo, G. A technical approach to the energy blockchain in microgrids. IEEE Trans. Ind. Inform. 2018, 14, 4792-4803. [CrossRef]

75. Munsing, E.; Mather, J.; Moura, S. Blockchains for decentralized optimization of energy resources in microgrid networks. In Proceedings of the 2017 IEEE Conference on Control Technology and Applications (CCTA), Mauna Lani, HI, USA, 27-30 August 2017; pp. 2164-2171.

76. Wang, N.; Xu, W.; Xu, Z.; Shao, W. Peer-to-peer energy trading among microgrids with multidimensional willingness. Energies 2018, 11, 3312. [CrossRef]

77. Wang, J.; Wang, Q.; Zhou, N.; Chi, Y. A novel electricity transaction mode of microgrids based on blockchain and continuous double auction. Energies 2017, 10, 1971. [CrossRef]

78. Khan, S.; Khan, R. Multiple authorities attribute-based verification mechanism for Blockchain mircogrid transactions. Energies 2018, 11, 1154. [CrossRef]

79. Niknam, T.; Golestaneh, F.; Malekpour, A. Probabilistic energy and operation management of a microgrid containing wind/photovoltaic/fuel cell generation and energy storage devices based on point estimate method and self-adaptive gravitational search algorithm. Energy 2012, 43, 427-437. [CrossRef]

80. Chakraborty, S.; Weiss, M.D.; Simões, M.G. Distributed intelligent energy management system for a single-phase high-frequency AC microgrid. IEEE Trans. Ind. Electron. 2007, 54, 97-109. [CrossRef]

81. Rahman, M.H.; Yamashiro, S. Novel distributed power generating system of PV-ECaSS using solar energy estimation. IEEE Trans. Energy Convers. 2007, 22, 358-367. [CrossRef]

82. Zhao, B.; Zhang, X.; Chen, J.; Wang, C.; Guo, L. Operation optimization of standalone microgrids considering lifetime characteristics of battery energy storage system. IEEE Trans. Sustain. Energy 2013, 4, 934-943. [CrossRef]

83. Su, W.; Wang, J.; Roh, J. Stochastic energy scheduling in microgrids with intermittent renewable energy resources. IEEE Trans. Smart Grid 2014, 5, 1876-1883. [CrossRef]

84. Chaouachi, A.; Kamel, R.M.; Andoulsi, R.; Nagasaka, K. Multiobjective Intelligent Energy Management for a Microgrid-Aymen Chaouachi-Academia. IEEE Trans. Ind. Electron. 2013, 60, 1688-1699. [CrossRef]

85. Wang, Z.; Chen, B.; Wang, J.; Begovic, M.M.; Chen, C. Coordinated energy management of networked microgrids in distribution systems. IEEE Trans. Smart Grid 2015, 6, 45-53. [CrossRef]

86. Chen, C.; Duan, S.; Cai, T.; Liu, B.; Hu, G. Smart energy management system for optimal microgrid economic operation. IET Renew. Power Gener. 2011, 5, 258-267. [CrossRef]

87. Fusheng, L.; Ruisheng, L.; Fengquan, Z. Microgrid Technology and Engineering Application; Academic Press: London, UK, 2014; ISBN 978-0-12-803598-6.

88. Justo, J.J.; Mwasilu, F.; Lee, J.; Jung, J.W. AC-microgrids versus DC-microgrids with distributed energy resources: A review. Renew. Sustain. Energy Rev. 2013, 24, 387-405. [CrossRef] 
89. Fregosi, D.; Ravula, S.; Brhlik, D.; Saussele, J.; Bosch Llc, R.; Frank, S.; Bonnema, E.; Scheib, J.; Wilson, E. A Comparative Study of DC and AC Microgrids in Commercial Buildings Across Different Climates and Operating Profiles. In Proceedings of the 2015 IEEE First International Conference on DC Microgrids (ICDCM), Atlanta, GA, USA, 7-10 June 2015; pp. 159-164.

90. Sechilariu, M.; Locment, F.; Wang, B. Photovoltaic electricity for sustainable building. Efficiency and energy cost reduction for isolated DC microgrid. Energies 2015, 8, 7945-7967. [CrossRef]

91. Liu, X.; Wang, P.; Loh, P.C. A hybrid AC/DC microgrid and its coordination control. IEEE Trans. Smart Grid 2011, 2, 278-286.

92. Gabbar, H.A. Smart Energy Grid Engineering; Academic Press: London, UK, 2017; ISBN 9780128053430.

93. Karki, N.R.; Karki, R.; Verma, A.K.; Jaeseok, C. (Eds.) Sustainable Power Systems: Modelling, Simulation and Analysis; Springer: Singapore, 2017; ISBN 9789811022296.

94. Mariam, L.; Basu, M.; Conlon, M.F. A Review of Existing Microgrid Architectures. J. Eng. 2013, $2013,937614$. [CrossRef]

95. Lu, X.; Wang, J.; Guo, L. Using microgrids to enhance energy security and resilience. Electr. J. 2016, $29,8-15$. [CrossRef]

96. Wasilewski, J. Optimisation of multicarrier microgrid layout using selected metaheuristics. Int. J. Electr. Power Energy Syst. 2018, 99, 246-260. [CrossRef]

97. Katiraei, F.; Iravani, R.; Hatziargyriou, N.; Dimeas, A. Microgrid Management. IEEE Power Energy Mag. 2008, 6, 54-65. [CrossRef]

98. Olivares, D.E.; Mehrizi-Sani, A.; Etemadi, A.H.; Cañizares, C.A.; Iravani, R.; Kazerani, M.; Hajimiragha, A.H.; Gomis-Bellmunt, O.; Saeedifard, M.; Palma-Behnke, R.; et al. Trends in microgrid control. IEEE Trans. Smart Grid 2014, 5, 1905-1919. [CrossRef]

99. Meng, L.; Sanseverino, E.R.; Luna, A.; Dragicevic, T.; Vasquez, J.C.; Guerrero, J.M. Microgrid supervisory controllers and energy management systems: A literature review. Renew. Sustain. Energy Rev. 2016, 60, 1263-1273. [CrossRef]

100. Bidram, A.; Davoudi, A. Hierarchical structure of microgrids control system. IEEE Trans. Smart Grid 2012, 3, 1963-1976. [CrossRef]

101. Shahidehpour, M.; Li, Z.; Bahramirad, S.; Li, Z.; Tian, W. Networked Microgrids: Exploring the Possibilities of the IIT-Bronzeville Grid. IEEE Power Energy Mag. 2017, 15, 63-71. [CrossRef]

102. Rojas, A.; Rousan, T. Microgrid control strategy: Derived from stakeholder requirements analysis. IEEE Power Energy Mag. 2017, 15, 72-79. [CrossRef]

103. Mahmoud, M.S.; Azher Hussain, S.; Abido, M.A. Modeling and control of microgrid: An overview. J. Franklin Inst. 2014, 351, 2822-2859. [CrossRef]

104. Shuai, Z.; Sun, Y.; Shen, Z.J.; Tian, W.; Tu, C.; Li, Y.; Yin, X. Microgrid stability: Classification and a review. Renew. Sustain. Energy Rev. 2016, 58, 167-179. [CrossRef]

105. Jimeno, J.; Anduaga, J.; Oyarzabal, J.; Gil de Muro, A. Architecture of a microgrid energy management system. Eur. Trans. Eelectr. Power 2010, 21, 1142-1158. [CrossRef]

106. Wang, C.; Liu, Y.; Li, X.; Guo, L.; Qiao, L.; Lu, H. Energy management system for stand-alone diesel-wind-biomass microgrid with energy storage system. Energy 2016, 97, 90-104. [CrossRef]

107. Maitra, A.; Pratt, A.; Hubert, T.; Weng, D.; Prabakar, K.; Handa, R.; Baggu, M.; McGranaghan, M. Microgrid controllers: Expanding Their Role and Evaluating Their Performance. IEEE Power Energy Mag. 2017, 15, 41-49. [CrossRef]

108. Ahmad Khan, A.; Naeem, M.; Iqbal, M.; Qaisar, S.; Anpalagan, A. A compendium of optimization objectives, constraints, tools and algorithms for energy management in microgrids. Renew. Sustain. Energy Rev. 2016, 58, 1664-1683. [CrossRef]

109. Fathima, A.H.; Palanisamy, K. Optimization in microgrids with hybrid energy systems-A review. Renew. Sustain. Energy Rev. 2015, 45, 431-446. [CrossRef]

110. Gamarra, C.; Guerrero, J.M. Computational optimization techniques applied to microgrids planning: A review. Renew. Sustain. Energy Rev. 2015, 48, 413-424. [CrossRef]

111. Tsikalakis, A.G.; Hatziargyriou, N.D. Centralized Control for Optimizing Microgrids Operation Central Controller Strategy to Optimize Microgrids Operation. In 2011 IEEE Power and Energy Society General Meeting; IEEE: Detroit, MI, USA, 2011; pp. 1-8. 
112. Chen, Y.-K.; Wu, Y.-C.; Song, C.-C.; Chen, Y.-S. Design and Implementation of Energy Management System With Fuzzy Control for DC Microgrid Systems. IEEE Trans. Power Electron. 2013, 28, 1563-1570. [CrossRef]

113. Jiang, Q.; Xue, M.; Geng, G. Energy management of microgrid in grid-connected and stand-alone modes. IEEE Trans. Power Syst. 2013, 28, 3380-3389. [CrossRef]

114. Parisio, A.; Rikos, E.; Glielmo, L. A model predictive control approach to microgrid operation optimization. IEEE Trans. Control Syst. Technol. 2014, 22, 1813-1827. [CrossRef]

115. Wang, Z.; Chen, B.; Wang, J.; Kim, J. Decentralized Energy Management System for Networked Microgrids in Grid-Connected and Islanded Modes. IEEE Trans. Smart Grid 2016, 7, 1097-1105. [CrossRef]

116. Teleke, S.; Baran, M.E.; Bhattacharya, S.; Huang, A.Q. Rule-based control of battery energy storage for dispatching intermittent renewable sources. IEEE Trans. Sustain. Energy 2010, 1, 117-124. [CrossRef]

117. Palma-Behnke, R.; Benavides, C.; Lanas, F.; Severino, B.; Reyes, L.; Llanos, J.; Saez, D. A microgrid energy management system based on the rolling horizon strategy. IEEE Trans. Smart Grid 2013, 4, 996-1006. [CrossRef]

118. Olivares, D.E.; Cañizares, C.A.; Kazerani, M. A Centralized Energy Management System for Isolated Microgrids. IEEE Trans. Smart Grid 2014, 5, 1864-1875. [CrossRef]

(C) 2019 by the authors. Licensee MDPI, Basel, Switzerland. This article is an open access article distributed under the terms and conditions of the Creative Commons Attribution (CC BY) license (http://creativecommons.org/licenses/by/4.0/). 